\title{
Laryngeal Dystonia, New Approaches for Direct Botulinum Toxin Administration
}

\author{
Luis Javier López Del Val ${ }^{1,}$ *, José Miguel Sebastián Cortes ${ }^{2}$, Elena Bellosta Diago ${ }^{1}$, \\ Sonia Santos Lasaosa ${ }^{1}$, Paúl Ricardo Vinueza Buitron ${ }^{1}$, Yolanda Lois Ortega ${ }^{2}$, Héctor Valles Varea ${ }^{2}$, \\ Elena López García ${ }^{1}$
}

${ }^{1}$ Neurology Service, Movement Disorders Unit, Hospital Clínico Universitario Lozano Blesa, Zaragoza, Spain

${ }^{2}$ Servicio de Otorrinolaringología, Hospital Clínico Universitario Lozano Blesa, Zaragoza, Spain

\section{Email address:}

javivineuro@telefonica.net (L. J. L. D. Val), jsebascor@hotmail.com (J. M. S. Cortes), elenabellosta@hotmail.com (E. B. Diago), ssantos@salud.aragon.es (S. S. Lasaosa), paulvinueza@Outlook.com (P.R. V. Buitron), yoliloisr@gmail.com (Y.L. Ortega), h.valles@telefonica.net (H. V. Varea), elelopezga@gmail.com (E. L. García)

${ }^{*}$ Corresponding author

\section{To cite this article:}

Luis Javier López Del Val, José Miguel Sebastián Cortes, Elena Bellosta Diago, Sonia Santos Lasaosa, Paúl Ricardo Vinueza Buitron, Yolanda Lois Ortega, Héctor Valles Varea, Elena López García. Laryngeal Dystonia, New Approaches for Direct Botulinum Toxin Administration. American Journal of Psychiatry and Neuroscience. Vol. 7, No. 3, 2019, pp. 52-5. doi: 10.11648/j.ajpn.20190703.11

Received: June 27, 2019; Accepted: August 12, 2019; Published: August 29, 2019

\begin{abstract}
To describe our experience in the treatment of laryngeal dystonia (in abduction and adduction), with special emphasis given to the technical aspects (approach procedure, dosage and type of botulinum toxin type A used), as well as treatment response and possible side effects. We conducted a cross-sectional descriptive study of a sample of patients with laryngeal dystonia treated by means of transoral administration of onabotulinumtoxinA or incobotulinumtoxinA over a period of 10 years (2007-2017). Data collected include demographic and clinical variables, treatment response (based on a self-rating scale), the duration of treatment and the appearance of side effects. Sample size: 15 patients (11 women; mean age: 44.06 years) with laryngeal dystonia (mean time since onset of 40 months; 12 patients with dystonia in adduction) and 174 administrations ( $92 \%$ incobotulinumtoxinA; average dosage of $5 \mathrm{U}$ in each vocal cord). The procedure took an average of 11.7 minutes to perform. Response was good in $31 \%$ of the procedures and very good in $57.5 \%$. Side effects were recorded in $14.4 \%$ of the procedures, although always mild and transitory, with a predominance of dysphagia and dysphonia. In our experience, transoral administration of botulinum toxin type A to treat laryngeal dystonia has proved to be a simple, quick, effective and safe technique.
\end{abstract}

Keywords: Botulinum Toxin A, Incobotulinumtoxin, Dystonia, Laryngeal Dystonia, Therapeutic Administration

\section{Introduction}

Laryngeal dystonia or spasmodic dysphonia (SD) has been included in the group of focal dystonias [1,2]. There are two main subtypes of SD with different symptoms: adductor SD and abductor SD. Adductor SD, the most common subtype, is caused by inappropriate hyper-adduction of the vocal cords leading to a strained and strangled voice quality, such that patients sound as though they are "trying to talk whilst being choked" (Crtichley M 1939; Jankovic and Fahn 2007). [3, 4]. (Abductor SD is less frequently observed and is caused by inappropriate hyper-abduction of the vocal cords leading to intermittent whispered, breathy phonation or aphonia.

Laryngeal dystonia, also known as spasmodic dysphonia (SD), is a focal dystonia, which affects $18 \%$ of patients with focal dystonia [5]. SD affects a small muscular area, which is not easily accessible by direct visual examination, and shares clinical and epidemiological characteristics, including tremor, circadian fluctuations and methods for relieving symptoms (e.g. "sensory tricks" such as singing or reciting to improve speech) with other focal dystonias [6]. Therefore, the diagnosis of SD relies on an experienced physician and should include a direct laryngeal examination to exclude any local pathology, together with a detailed medical history and 
description of clinical symptoms taken from the patient. [7].

It has been 25 years since the first communications about treatment with neurobotulinum toxin of type A (BoNT) in patients with laryngeal dystonia of adduction. The use of BoNTA to treat patients with adductor SD was first described in 1986. Currently, BoNT-A is the gold standard treatment for this pathology, producing a marked positive response [8]. Although, the evidence for therapeutic benefit is limited to only one randomised, controlled study in a small number of patients, assessing dosage and administration techniques [9]. In general, patients show good clinical responses to botulinum toxin in spectrographic voice analysis.

The few adverse events (AEs) reported were temporary and included dysphagia for liquids, dyspnoea and decreased voice volume [10]. No controlled studies in patients with abductor SD have been reported; however, non-controlled case series suggest that BoNT-A has less benefit in patients with abductor SD than in those with adductor SD (Blitzer et al. 1998). [7].

The limited number of studies in patients with adductor SD may be explained by a lack of reliable clinical scales for assessment of symptom severity and improvement: voice analysis is not a validated or reliable assessment measure.

Furthermore, there are no standard protocols for injection of BoNT-A in patients with SD. Injection of BoNT-A into the vocal cords is technically difficult and BoNT-A dose and the requirement for unilateral or bilateral injections varies between patients, adding to the complexity [8]. As a result, BoNT-A injections are usually administered transcutaneously with or without electromyographic (EMG) guidance, transorally or naso-endoscopically [8].

Studies have shown that the method of injection used does not impact the efficacy of BoNT-A treatment when the injections are administered by experienced clinicians $[11,12]$.

Therefore, in most cases the therapeutic approach for patients will depend on the individual experience of each physician. Our group published a review of the techniques existing therapies [13].

The transcutaneous method is the oldest and easiest to perform [7, 9]. In this method BoNT-A is injected into the thyroarytenoid adductor muscle through the cricothyroid membrane, usually under EMG-guidance [12]. Usually the needle must be connected to the monitor electromyography to detect the muscle and perform at that time infiltration of BONT [12].

Generally, bilateral injections are administered in order to use lower doses of BoNT-A [9] while maintaining the clinical benefit of larger doses [13]. The doses used are very small and can increase in successive infiltrations according to the response obtained.

The absence of images is the main disadvantage of this method and, even with EMG guidance, the cricoarytenoid muscle is difficult to locate. This, and displacement of the needle when injections are performed, may account for the response failure rate of $20 \%$ reported for this method [7].

In contrast, although more complex, the transoral method is safe and effective, with better outcomes than the transcutaneous method [14-17]. Transoral injection of BoNT-
A is performed under local or general anaesthesia using fibroscopy to directly visualise injection of the thyroarytenoid muscle. BoNT-A doses administered, duration of effect and reported AEs are similar for these methods.

No specific material is available to perform this technique, but guides are used curves that can be prepared with a curved cannula rigid inside which can be adapted a long flexible trocar connected to a syringe with BONT.

The recommended dose of BONT, the duration of the effect and the possible adverse effects are similar [18].

Our objective is to describe our experience in the treatment of laryngeal dystonia: the technic aspects (boarding procedure, dose and type of BONT used), as well as the response to treatment and the possible adverse effects.

\section{Patients and Methods}

This was a transversal, descriptive study in adult patients (sample of 15 patients) with SD evaluated at the Movement Disorders Unit of our hospital during a 10 year period from 2007 to 2017. The study was performed within our daily clinical work at the Movement Disorder Unit. Clinical variables were collected (age at the time of diagnosis, sex, type of laryngeal dystonia and time of evolution) and techniques (dose of BONT, administration time, procedure used, response and side effects).

BoNT-A treatment was administered by an interdisciplinary team, consisting of a neurologist (reconstitution and preparation of BoNT-A and injection into the vocal cords) and two otolaryngologists (imaging of the injection site using fibre endoscopy, anaesthesia and correct needle placement). Anaesthesia was performed following standard otorhinolaryngology procedures with $10 \%$ aerosolised lidocaine for the oropharynx and 5\% lidocaine dispensed using the Laryngo-Tracheal Mucosal Atomisation Device (LMA/MADgic ${ }^{\circledR}$, Wolfe Tory Medical Inc, Salt Lake City, USA) for the hypopharynx and larynx, ensuring a more pronounced and reliable anaesthesia and greater cooperation from the patient. Injections were administered using a Chiba Needle inserted into a curved cannulated guide designed in our hospital. Figure 1.

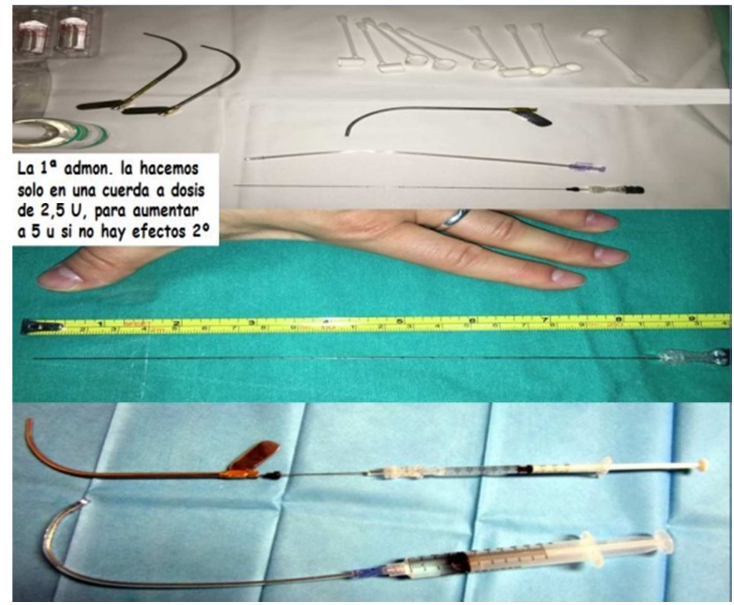

Figure 1. Material used for the transoral administration. 
Once adequate placement into the vocal cord was achieved, the neurologist performed the injection and subsequently removed the needle and guide.

Regarding the type of BONT, during the first treatments onabotulinumtoxin A was used

A (OnabotA), later we changed to incobotulinumtoxinA (IncobotA).

Patients received transoral injections of 2.5 International Units (IU) of onabotulinumtoxin $A$ (Botox ${ }^{\circledR}$, Allergan Inc), or incobotulinumtoxinA (Xeomin ${ }^{\circledR}$, Merz Pharmaceuticals $\mathrm{GmbH}$ ) into a single vocal cord under local anaesthesia at the first treatment to evaluate possible AEs.

For the second treatment an increased dose of 5 IU or 7.5 IU incobotulinumtoxinA was injected into both vocal cords.

In general, most patients received doses of approximately 5 IU BoNT-A per vocal cord, with an increased dose in one vocal cord in comparison to the contralateral cord; however, repeat doses varied from one patient to the next depending on the efficacy of treatment and the development of AEs.

For the statistical analysis the program was used SPSS v. 22.0, including the Mann-Whitney $U$ for difference of means or chi squared with test Fisher for proportions.

Table 1. Individual description of cases.

\begin{tabular}{|c|c|c|c|c|c|c|c|c|c|c|c|}
\hline & \multirow{2}{*}{$\begin{array}{l}\text { Age } \\
\text { (years) }\end{array}$} & \multirow{2}{*}{$\begin{array}{l}\text { Gende } \\
\mathbf{r}\end{array}$} & \multirow{2}{*}{$\begin{array}{l}\text { Beginning } \\
\text { age (years) }\end{array}$} & \multirow{2}{*}{$\begin{array}{l}\text { Dystonia } \\
\text { type }\end{array}$} & \multirow{2}{*}{$\begin{array}{l}\text { Number of } \\
\text { administratio } \\
\text { ns (total: 174) }\end{array}$} & \multicolumn{2}{|c|}{$\begin{array}{l}\text { Dose of botulinum } \\
\text { toxin type } A(U)\end{array}$} & \multicolumn{2}{|c|}{ Duaration (months) } & \multicolumn{2}{|c|}{$\begin{array}{l}\text { Treatment time } \\
\text { (minutes) }\end{array}$} \\
\hline & & & & & & Min & Max & Min & Max & Min & Max \\
\hline Patient 1 & 38,63 & Female & 28,83 & laryngeal & 15 & 0 & 5 & 4 & 31 & 8,3 & 25 \\
\hline Patient 2 & 58,98 & Male & 49,98 & laryngeal & 11 & 0 & 5 & 2 & 11 & 9 & 35 \\
\hline Patient 3 & 79,84 & Female & 62,55 & laryngeal & 33 & 0 & 3 & 4 & 6 & 2,3 & 15 \\
\hline Patient 4 & 73,49 & Female & 59,28 & laryngeal & 20 & 0 & 5 & 4 & 8 & 5 & 15 \\
\hline Patient 5 & 67,86 & Male & 19,73 & laryngeal & 8 & 0 & 3 & 3 & 6 & 4 & 10 \\
\hline Patient 7 & 44,36 & Female & 37,57 & in abduction & 6 & 0 & 5 & 4 & 5 & 5 & 14 \\
\hline Patient 8 & 81,44 & Female & 74,12 & laryngeal & 7 & 0 & 5 & 4 & 5 & 5 & 20 \\
\hline Patient 9 & 60,98 & Male & 35,96 & laryngeal & 9 & 0 & 5 & 5 & 5 & 3 & 8 \\
\hline Patient 10 & 61,33 & Female & 51,30 & laryngeal & 14 & 0 & 7,5 & 3 & 5 & 4 & 17 \\
\hline Patient 11 & 39,83 & Female & 24,10 & cervical focal & 13 & 0 & 5 & 4 & 5 & 8 & 18 \\
\hline Patient 12 & 40,30 & Female & 19,57 & centralized & 29 & 0 & 5 & 4 & $\begin{array}{l}\text { prolonged } \\
\text { remission }\end{array}$ & 5 & 25 \\
\hline Patient 14 & 37,83 & Female & 35,64 & in abduction & 2 & 0 & 5 & 3 & 4 & 9 & 12 \\
\hline Patient 15 & 34,68 & Male & 32,82 & in abduction & 2 & 0 & 5 & 4 & 4 & 6 & 8 \\
\hline
\end{tabular}

\section{Results}

A total of 15 patients (11 female, $73.3 \%$ ) were assessed during the study period. Patient characteristics are summarised in Table 1. At diagnosis, patients had a mean age of 44.06 years (range: $34-54$ years) and the mean time since onset of symptoms to diagnosis was 40.0 months, a long delay in comparison to other otolaryngology disorders.

The described data are related to 174 therapeutic administrations for a ten year period.

All patients were diagnosed with laryngeal dystonia, most (10 patients, 66.7\%) with the more common adductor subtype. In one patient SD was integrated in a process of generalised dystonia and in another patient SD was accompanied by cervical dystonia.

A total of 174 administrations of BONT have been carried out, $92 \%$ with IncobotA and the $8 \%$ remaining with OnabotA The average dose of BONT was $4.9 \pm 0.48 \mathrm{U}$ in a vocal cord (range: $2.5-7.5 \mathrm{U}$ ) and $4.0 \pm 2.12 \mathrm{U}$ In the opposite. The mean duration of the procedure (understood as time elapsed since the patient entered the consultation until he went home) was $11.7 \pm 7.06 \mathrm{~min}$; in the procedures with OnabotA the mean duration was $17.92 \pm 8.04 \mathrm{~min}$, and for IncobotA of $12.3 \pm 7.41 \mathrm{~min}$; the difference was statistically significant and attributable to the learning curve of the technique.

Different treatments have been added, such as concomitant medication or facilitators administered previously to the injection of BONT: anxiolytics in three patients and subcutaneous atropine to control the hypersalivation in three other cases.

The average duration of the therapeutic effect has been estimated at $5.25 \pm 2.29$ months. In one patient was registered a period of spontaneous remission of 31 months after a pregnancy with subsequent recurrence. In the patients initially treated with OnabotA that later passed to IncobotA, the average duration of the response was $4.76 \pm 1.16$ and $5.57 \pm 2.87$ months, respectively $(\mathrm{p}=0.465)$.

The therapeutic response was assessed subjectively using a self-administered scale with a score of 1 to $5: 1$, not titrable; 2 , scarce; 3, moderate; 4, remarkable; and 5, high. So, globally, the improvement was scarce in two administrations $(1.1 \%)$, moderate in $18(10.3 \%)$, remarkable in $54(31 \%)$ and high in $100(57.5 \%)$. When differentiating according to the BONT used, for OnabotA improvement was scarce in $14.3 \%$, moderate in $57.1 \%$ and remarkable in $28.6 \%$. The percentages of remarkable and high responses were greater in patients treated with IncobotA $(30.4 \%$ and $63.3 \%$, respectively).

Regarding the adverse effects referred to by our patients, they were present in $14.4 \%$ of the procedures (17 for OnabotA and 19 for IncobotA; $p<0.0019$ ). In our case, the first 14 treatments were performed with OnabotA, and dysphagia was recorded in $64.3 \%$, dysphonia in $14.3 \%$, 
choking in $21.4 \%$ and cough in $21.4 \%$. All cases were mild and transient, but one patient refused to continue with the treatment. In the subsequent 160 administrations IncobotA was used without modifying the technique. Adverse effects were recorded in 19 cases, classified also as mild $(5.2 \%$ dysphagia, $5.2 \%$ dysphonia and $1.5 \%$ choking).

\section{Discussion}

There are many and different reasons for the limited number of trials in laryngeal adduction dystonia: the lack of reliable clinical scales for the assessment of the intensity of the symptoms, the difficulty for acoustic analysis and heterogeneity in the technique (dose and type of BONT, as well as procedure of infiltration) [8].

In this study we report our experience of transoral administration of a total of 174 BoNT-A injections in 15 patients diagnosed with laryngeal dystonia over a 10-year period.

In comparison to a previous publication, in which the average duration of treatment efficacy was reported to be approximately 120 days (4 months) for both unilateral and bilateral BoNT-A injections [14]. In our study, the duration was prolonged to approximately 5.3 months, which may be related to the better accuracy of BoNT-A administration using the transoral method. Patient age and gender had no effect on this response, which is in agreement with another study showing that BoNT-A dosage and duration of therapeutic benefit do not vary with age or gender [19].

The mean BoNT-A dose required ranged from 5 to $10 \mathrm{IU}$ and in our patients the therapeutic response was maintained in a constant and uniform way. However, in a published study in patients with $\mathrm{SD}$, it was necessary to increase BoNT-A doses to maintain treatment efficacy with disease progression, in contrast to patients with cervical dystonia who require a gradual increase in BoNT-A doses to maintain treatment efficacy [20].

In this sense, in more complex dystonias with involvement of more muscle groups, Jankovic et al relate the loss of therapeutic effect of BONT with the dose used and the administration interval [9]. By that time, a lower response is related to a higher dose of BONT and shorter time intervals. In dystonia laryngeal, this phenomenon is infrequent, possibly for the lower doses of BONT.

Recently an update has been published on different treatments with botulinum toxin in dystonia, in which the authors coincide with our work by stating that the safest way and effective to treat a laryngeal dystonia is the transoral [21], something that was already beginning to venture in a 1995 publication [22].

In our study, the incidence of AEs was generally low, and the reported AEs were mild and of a transient nature; although a much higher incidence was reported after the initial onabotulinumtoxinA injections compared with later injections of incobotulinumtoxinA. Additional controlled studies in a larger patient population are required to investigate this difference further. Only one patient refused to continue with the treatment.

\section{Conclusions}

We found that transoral BoNT-A injections were safe and effective and could be performed rapidly with a mean time of 11.79 minutes to perform each injection. It guarantees total precision at the site of injection of the toxin.

In addition, greater comfort for the patient was achieved through the local anaesthetic procedure. In our opinion the experience of the clinical team, combined with other factors such as patient relaxation, intensity of the emetic reflex and hyper-salivation, is key to considerably reducing the time taken to perform the BoNT-A injections.

Transoral BoNT-A injectionwith local anaesthesia is a safe and effective treatment option for patients with SD (both adduction and abduction forms) with advantages over other therapeutic approaches (transcutaneous or transoral injections under general anaesthesia) with respect to cost in time and healthcare resources. The accuracy of injection placement with this method ensures high efficacy (over 90\%) in patients with SD and the need of lower doses.

\section{Conflict of Interest}

Dr. López del Val reported no conflicts of interest. The authors alone are responsible for the content and writing of the paper.

\section{References}

[1] Tarsy D, Simon DK. Dystonia. N Engl J Med 2006; 355: 818 29.

[2] L. J. López del Val, et al of botulinum toxin for the treatment of focal laryngeal dystonia (spastic dysphonia). Laryngoscope 1988; 98: 193-7.

[3] Critchley M. Spastic dysphonia ('inspiratory speech'). Brain. 1939; 62: 96-103.

[4] Jankovic J, Fahn S. Dystonic disorders. In Jankovic J, Tolosa E, eds. Parkinson's disease and movement disorders. 5 ed. Philadelphia: Williams \& Wilkins; 2007. p. 331-57.

[5] Bartolomé FM, Fanjul S, Cantarero S, Hernández J, GarcíaRuiz PJ. Distonías focales primarias: estudio descriptivo de 205 pacientes. Neurologia 2003; 18: 59-65.

[6] García-Ruiz Espiga PJ. Distonía laríngea y faríngea. In López del Val LJ, Castro-García C, eds. Toxina botulínica. Aplicaciones terapéuticas en el siglo xxi. 2 ed. Barcelona: Elsevier Masson; 2010. p. 151-6.

[7] Blitzer A, Brin MF, Stewart CF. Botulinum toxin management of spasmodic dysphonia (laryngeal dystonia): a 12-year experience in more than 900 patients. Laryngoscope 1988; 108: 1435-41.

[8] Ludlow C. Treatment of laryngeal disorders and oromandibular dystonia. In: Toxins 2012: basic science and clinical aspects of botulinum and other neurotoxins. Miami Beach; 2012. 
[9] Jankovic J, Schwartz K. Clinical correlates of response to botulinum toxin injections. Arch Neurol 1991; 48: 1253-6.

[10] Novakovic D, Waters HH, D'Elia JB, Blitzer A. Botulinum toxin treatment of adductor spasmodic dysphonia: longitudinal functional outcomes. Laryngoscope 2011; 121: 606-12.

[11] Elmiyeh B, Prasad VM, Upile T, Saunders N, Youl BD, Epstein R, et al. A single-centre retrospective review of unilateral and bilateral Dysport injections in adductor spasmodic dysphonia. Logoped Phoniatr Vocol 2010; 35: 39 44.

[12] Fulmer SL, Merati AL, Blumin JH. Efficacy of laryngeal botulinum toxin injection: comparison of two techniques. Laryngoscope 2011; 121: 1924-8.

[13] López-García E, Martínez-Martínez L, Lopez del Val LJ. Distonía laríngea: actualización del tratamiento con toxina botulinica. Revista Española de Trastornos del Movimiento 2013; 5: 20-2.

[14] Blitzer A. Spasmodic dysphonia and botulinum toxin: experience from the largest treatment series. Eur J Neurol 2010; 17 (Suppl 1): S28-30.

[15] García-Ruiz C, Cenjor-Español R, Sánchez-Pernaute R, Astarioa V, Sánchez-Bernados J, García de Yébenes P. Distonía laríngea. Tratamiento con toxina botulínica mediante técnica transcutánea y transoral. Estudio comparativo. Neurologia 1996; 11: 216-9.

[16] García-Ruiz PJ, Sánchez del Río M, Cenjor-Español C,
Sanabria-Brassart J, Sánchez-Bernados V, Astarloa-Gómez R, et al. Disfonía espástica de aducción: clínica y tratamiento. Rev Clin Esp 1998; 198: 156-8.

[17] Rhew K, Fiedler DA, Ludlow CL. Technique for injection of botulinum toxin through the flexible nasolaryngoscope. Otolaryngol Head Neck Surg 1994; 111: 787-94.

[18] García-Ruiz PJ, Cenjor-Español C, Sánchez-Bernardos V, Astarloa R, Sanabria J, García de Yébenes J. Botulinum toxin treatment for spasmodic dysphonia: percutaneous versus transoral approach. Clin Neuropharmacol 1998; 21: 196-8.

[19] Vasconcelos S, Birkent H, Sardesai MG, Merati AL, Hillel AD. Influence of age and gender on dose and effectiveness of botulinum toxin for laryngeal dystonia. Laryngoscope 2009; 119: 2004-7.

[20] García-Torres MA, Echeverría-Urabayen A, Contreras A, Carnal-Martín P, García-Ruiz E. Evolución a largo plazo de la dosis de toxina botulínica en las distonías laríngea y cervical. Rev Neurol 2005; 41: 525-6.

[21] García-Ruiz PJ, Sanz-Cartagena P, Martínez-Castrillo JC, Ares-Pensado B, Avilés-Olmos I, Blázquez-Estrada M, et al. Mitos y evidencias en el empleo de la toxina botulínica: neurofarmacología y distonías. Rev Neurol 2018; 66: 163-72.

[22] Brin MF, Blitzer A, Stewart A, Diamond B, Lovelace RE. Botulinum toxin for spasmodic dysphonia: double blind placebo-controlled assessment of dose and technique. Mov Disord 1995; 10: 135-7. 